\title{
Exploring the impact of the COVID-19 pandemic on approaches to innovation in the consulting industry: a grounded theory pilot study
}

\author{
Diane Laurette Kamning \\ Sullivan University, Louisville, Kentucky, USA
}

Innovation in the consulting industry

Received 10 May 2021

Revised 13 August 2021

18 September 2021

29 October 2021

Accepted 23 November 2021

\begin{abstract}
Purpose - There is a significant pressure on consulting businesses to produce innovative solutions and to assist their clients in producing innovative solutions for their organizational problems as well. In addition to that challenging need to innovate for survival and competition, as other contemporary firms, consultancies must face the global changes brought by the outbreak of the coronavirus infection since 2019. This qualitative pilot study aimed at exploring the impact of the coronavirus disease 2019 (COVID-19) pandemic on the approaches to innovation in the consulting industry.

Design/methodology/approach - Triggered from the literature gap on approaches to innovation in consultancies during the unprecedented COVID-19 pandemic, a grounded theory approach was used to generate a theoretical explanation of how the COVID-19 is affecting the strategies and approaches of businesses in harnessing innovation opportunities from the perspectives of four professionals from an information technology (IT) consultancy in the USA.

Findings - The findings of this pilot study showed that organizational leaders' increased responsiveness, a Job-To-Be-Done strategy, organizational support and team adaption are the keys to harvesting dynamic capabilities for better competition, even during global environmental changes.

Practical implications - This implies that managers remain the main actors in a firm's efforts to harvest dynamic capabilities. Innovation strategists, business leaders and policymakers can confidently work together to implement novel and flexible work settings that integrate both social and economic advancements.

Originality/value - Theoretical implications support the sustainable innovation strategy concepts and the Job-To-Be-Done theory. Finally, the substantive theory from this pilot study lays the ground for future research on approaches to innovation in the consulting industry.
\end{abstract}

Keywords COVID-19 pandemic, Job-To-Be-Done theory, Dynamic capabilities, Telework, Consulting, Innovation opportunities, B2B, Grounded theory

Paper type Research paper

\section{Introduction}

According to Luecke and Katz (2003), innovation can be perceived as the root idea or knowledge that led to the production of a novel product, process or service that adds value.

Many established companies that are pressured to grow still find it challenging to produce novel ways to gain money (Parmar, Mackenzie, Cohn, \& Gann, 2014). To create new business ideas, a common business model to innovation encompasses more than one of the innovation patterns that emerged from the explosion of digital data and the availability of cutting-edge data tools (Parmar et al., 2014). Also, pursuing innovation is frustrating for most companies

(C) Diane Laurette Kamning. Published in Innovation \& Management Review. Published by Emerald Publishing Limited. This article is published under the Creative Commons Attribution (CC BY 4.0) licence. Anyone may reproduce, distribute, translate and create derivative works of this article (for both commercial and non-commercial purposes), subject to full attribution to the original publication and authors. The full terms of this licence maybe seen at http://creativecommons.org/licences/by/4.0/ legalcode

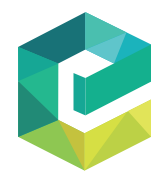

Innovation \& Management Review Emerald Publishing Limited DOI 10.1108/INMR-05-2021-0076 
because even successful corporations have high innovation failure rates and are not able to sustain their performance (Pisano, 2015). According to Pisano (2015), the core cause of that innovation problem is the tendency of firms to adopt trending best practices or to mimic the prevailing epitome innovator, instead of implementing and communicating an innovation strategy that is aligned with each firm's business strategy. When creating an innovation strategy, it is important to determine the innovation value creation approach for potential clients, the firm capture or seizure approach for that value and the kind(s) of innovation to pursue (Pisano, 2015).

Shifting to a Job-To-Be-Done strategy can help firms locate opportunities from their clients and succeed in their innovation process (Christensen, Hall, Dillon, \& Duncan, 2016). As a result, firms like consultancies which are driven by value-creation initiatives should excel at innovation. In fact, being a category of knowledge-intensive business service, consultancies constitute not only a valuable source of innovation for their clients, but also an essential factor for national and regional innovation systems (Santos, 2019). In addition, the consulting industry was the major contributor of the USA economy because it was a fast-growing, dynamic and innovative business sector (Apostolou \& Mentzas, 1999).

However, in the 21st century, the coronavirus disease 2019 (COVID-19) pandemic struck the world in an unprecedented way, affecting every individual, every activity, every business and every location (Euchner, 2020). Digital reinvention has been taking over multiple domains during the COVID-19 lockdown with, for example, distance learning from prekindergarten to career training, the proliferation (in all business sectors including fitness training) of the trends of telework (which used to be a privilege for high-tech professionals pre-COVID), telehealth coverage by all insurances temporarily in the health domain, and in manufacturing a need for the ability to remotely diagnose equipment is pushing manufacturers to build a strong business case for the integration of the Internet of things and other smart manufacturing technologies into their systems (Euchner, 2020). Furthermore, Euchner (2020) called for innovators to take advantage of the benefits of the current digital assets and to redesign the world such as to fully exploit the changes brought by the pandemic, instead of trying to bring things back to the way they were pre-COVID. As a result, business leaders should find ways to take advantage of the current digital reinvention opportunities to innovate and create sustainable competitive advantages.

With the ongoing COVID-19 pandemic, its newness, the unavailability of vaccines and cures against the COVID-19 virus so far, there is a literature gap about the impact of the COVID-19 pandemic on approaches to innovation in the consulting industry. The research question of this study was:

RQ1. What is the impact of the COVID-19 pandemic on harnessing innovation opportunities in the consulting industry?

The purpose of this pilot study was to examine the changes brought by the COVID-19 pandemic on approaches or models to business innovation in the consulting industry. The goals of the study were:

(1) To identify and examine the approaches taken by consultancies in recognizing and exploiting business innovation opportunities during the COVID-19 pandemic

(2) To identify some capabilities of businesses to recognize and exploit business innovation opportunities post-COVID, in order to guide innovation strategists, policymakers, business leaders and scholars

(3) To test the Job-To-Be-Done theory and advance the dynamic capabilities research using real-world business responses to the impact of the COVID-19 on business innovation capabilities and practices. 
Definition of key terms

Innovation. Translation of an idea into a new product, method or service that creates value for the customer and/or the society (Moore, 2005).

Harnessing innovation opportunities. Recognizing and exploiting innovation opportunities (Burkus, 2013).

\section{Literature review}

The conceptual framework of this study relies on existing knowledge on the COVID-19 pandemic, innovation in consultancies, importance of consultancies and the Job-To-Be-Done theory.

\section{The COVID-19 pandemic}

The COVID-19 virus infection started at the end of 2019 in a seafood market located in Wuhan City, Hubei province in China (Pillai, Nagappan, Dharani, Subramanian, Champakesan, \& D'Cruz, 2020). Its outbreak was declared a global public health emergency by the World Health Organization at the end of January 2020 and then a pandemic in March 2020 (Jiang, Jiang, Tong, \& Zhou, 2020). The COVID-19 pandemic spread globally, infecting 5.73 million people and causing deaths of approximately 361 thousand people by the 26th of May 2020 (Jiang et al., 2020). In addition, the pandemic brought significant socio-economic issues to each country around the world including reduced business operations in many industries, strained healthcare systems, mental health problems and issues getting provisions (Pillai et al., 2020). Government, CDCs (Centers for Disease Control and Prevention), emergency organizations and researchers have thrown themselves into multiple projects to quickly find preventive and curative measures against that virus. So far, there have been lockdowns, mental breakdowns, curfews, furloughs, incessant testing, quarantines, social distancing measures and increase in remote work trends (Euchner, 2020).

\section{Innovation}

Change and importance of innovation. Max Weber, the renowned sociologist of German origin, stated at the very beginning of the 20th century that the "fate of our times is characterized by rationalization and intellectualization and, above all, the disenchantment of the world" (Hamel, 2015, p. 6). This seems to be true even in the 21st century according to Hamel (2015). In fact, for Hamel (2015), innovation begins with the heart and the greatest innovations in both the social and the economic domain originated from the pursuits of honorable and timeless ideals such as wisdom, sustainability, community and equality.

Alves, Galina, and Dobelin (2018) stated that organizational innovation is still neglected in favor of technological innovation. However, organizational innovation is also an important type of innovation. It mainly touches business practices, workplace organization and external relations. Alves et al. (2018) found from their bibliometric analyses that the focus in organizational innovation research shifted from learning as a process and knowledge as a resource for innovation in the past, to the association of organizational innovation to knowledge and capability in the present. This pilot study focused on approaches to any type of innovation.

Since the beginning of the 20th century, many novel phenomena like digitalization, globalization and artificial intelligence have transformed the world because organizations and individuals have been connected across geographies, institutions and industries (Filatotchev, Aguilera, \& Wright, 2020). As a result, companies have changed their innovation strategies and governance strategies. In fact, innovation is important for competitive advantage, brand development and growth (Moore, 2005). Also, innovation and corporate governance are interwoven and are at the heart of each organization. In addition, governance innovations cause the evolution of regulations. Therefore, innovation is vital for firm competition and for the survival of businesses, their embedding environments and countries. In fact, an innovative product, service, system or method creates value for the
Innovation in the consulting industry 
customer, generates profit for the shareholders and help advance the society. Any economic growth in companies located in a country contribute to the economic growth of that country (Filatotchev et al., 2020).

Corporate governance plays an important role in determining companies' research and development (R\&D) activities as corporate governance affects the choice of risk/return level of managers as well as their short-term and long-term incentives (Filatotchev et al., 2020). However, during the COVID-19 pandemic, some firms invested their R\&D resources into medical research. Governments and some private companies have been collaborating on the quest for therapies, vaccines and countermeasures against the coronavirus (Filatotchev et al., 2020; Pillai et al., 2020). According to Filatotchev et al. (2020), the open-systems tactic to governance innovations can generate natural fruitful conversations on possible ways to view private/public partnerships from a corporate governance angle.

Collaborative innovation. During innovation strategies' design, the innovative landscape map of Pisano (2015) can assist business leaders in deciding on the appropriate efforts to invest for their specific company in business model innovation and in technological innovation:

(1) A disruptive innovation, such as ride-sharing services and video on demand, requires a new business model and leverages existing technical competencies

(2) A routine innovation, such as a new Pixar 3-D animated film, leverages the existing business model while leveraging existing technical competencies as well

(3) An architectural innovation, such as digital imaging and personalized medicine, requires a new business model and requires new technical competencies

(4) A radical innovation, such as biotechnology, jet engines or the fiber-optic cable, leverages the existing business model, but requires new technical competencies.

The cooperative partnership innovation is an innovation model which helps maximize the wins of all the involved companies, build a long and trustful relationship based on collaboration, and share opportunities, risks as well as information (Lin, Zhang, Yan, \& Jiang, 2020).

There is a growing number of firms engaging in collaborative innovation to mainly produce technological innovation visible as new products or services that can create value and a competitive advantage (Cui, Tong, Teo, \& Li, 2020). This engagement aims at complementing internal organizational efforts in the development of novel product or service. For example, the pharmaceutical firm Pfizer collaborates with IBM on innovative distant monitoring gears for Parkinson's diseases where IDM brings in complex data analysis abilities and Pfizer brings in their medical expertise. Inter-firm collaborative innovation combines knowledge from multiple parties and its outcomes rely heavily on the interfirm knowledge distance which Cui et al. (2020) defined as "the degree of Research and Development (R\&D) domain knowledge unrelatedness between two collaborating firms" (p. 217). There is a potential to offer fresh ideas to the innovation process via knowledge recombination or access to market insights that are normally unavailable to a company when working with a knowledge distant collaborator that has R\&D domain knowledge from an unrelated field (Cui et al., 2020).

However, companies keep struggling to benefit from inter-firm collaborative innovation with issues like bad knowledge integration when there is high interdependence between knowledge distant collaborators, delays, low collaborative innovation efficiency and collaboration abandonment (Cui et al., 2020). Collaborative innovation companies use information technology (IT) to exchange knowledge and interact. Cui et al. (2020) conducted a multi-method study to investigate the discriminating roles of IT capabilities in moderating the effects of inter-firm knowledge distance on project performance in the context of collaborative innovation projects involving two collaborating companies. 
Cui et al. (2020) based their work on the absorptive capacity theory and produced three ITenabled inter-firm knowledge capabilities: IT-enabled inter-firm knowledge exploitation capability (IT-KIC), IT-enabled inter-firm knowledge exploration capability (IT-KRC) and ITenabled inter-firm social integration capability (IT-SIC) in a collaborative innovation setting. Cui et al. (2020) added that cultural contextualization is also an important factor because there is an emphasis on explicit knowledge for Westerners while there is a stress on tacit knowledge for Easterners.

\section{Consulting industry}

Job-To-Be-Done theory. According to the Job-To-Be-Done theory, detecting the poorly performed jobs in clients' lives and designing solutions (product, procedure, experience, etc.) around those jobs constitute the heart of a successful innovation (Christensen et al., 2016). That explains the innovation failures of many firms, especially the firms capitalizing on customer behavior analysis.

Ribeiro, Monteiro and Luttembarck (2018) postulated that firms from business-tobusiness (B2B) systems tend to adopt value-creation strategies aimed at client loyalty. From the outcomes of their multimethod research study, Ribeiro et al. (2018) affirmed that jobs relevant to the client yield improved job performance and increases the co-created value, hence joining the Job-to-be-done theory. Ribeiro et al. (2018) proposed the Job-To-Be-Done technique as a method to support the implementation of the Service Dominant Logic concepts. Moreover, it is possible for the company to increase the co-created value by observing moderating elements in the context of the client's management like professionalization of the management.

Innovation as a vital element to the survival of a consulting firm. There is a significant pressure on consulting enterprises to generate innovative solutions and also to assist their customers generate innovative solutions for their organizational problems. Crowdsourcing recently emerged as a potential novel approach to help in the originating and fostering of innovative thinking and of innovations. O'Leary (2019) conducted a case study research to examine the use of crowdsourcing for innovation in consulting companies and to determine the effects of crowdsourcing on the organizational model of consulting. O'Leary (2019) found that the participation of consultants in crowdsourcing exercise has strengths like the opening of communication lines and the broadening of perspectives, and limitations like the questioning of employee productivity by the manager and potential crowd information influence on stock market transactions. Ways that crowdsourcing was implemented included partnering with Software vendors, evolving platforms, idea generation software, mobile computing, and "always on" crowdsourcing or crowdsourcing as a decision support system. However, some research and accounting issues render the implementation of enterprise crowdsourcing difficult (O'Leary, 2019).

Impact of consulting services on industries. Bruhn, Karlan and Schoar (2018) conducted a longitudinal study to examine if there is a direct effect on the performance of small companies in emerging markets when constrictions of managerial capital are lightened, and if yes to determine the most important dimension of managerial capital for company performance. That research also aimed at investigating the impact of consulting services on small and medium firms. After setting up a randomized controlled trial in Puebla, Mexico, Bruhn et al. (2018) constituted a sample of 432 micro, small and medium companies out of which 282 formed a control group and 150 received the treatment with subsidized consulting services. Bruhn et al. (2018) aimed at growing the managerial skills of the owner-managers by giving them access to subsidized mentoring and consulting services. One of the findings of Bruhn et al. (2018) was that the consulting intervention has a positive short-run effect on the return on assets (ROA), productivity and profits of the companies in the treatment group in the oneyear follow-up.
Innovation in the consulting industry 
Hinged on an index of entrepreneurial spirit, Bruhn et al. (2018) concluded that the alterations from the trial on the firms led to enhancement in the overall confidence and control that micro, small and medium-sized company owners have in their business. In addition, there is potential for management consulting companies to obtain high returns from servicing micro, small and medium-sized companies. However, Bruhn et al. (2018) proposed that the nonexistence of market transactions in consulting services is due to funding limitations and the uncertainty about the benefits of the services.

This research by Bruhn et al. (2018) has similarities with the study of Bloom, Nicholas, Benn Eifert, Aprajit Mahajan, David McKenzie and John Roberts in 2013 on the effects of intensive consulting services from an international management consulting company on the business practices of large Indian textile companies.

\section{Methodology}

With the ongoing COVID-19 pandemic, its newness, the unavailability of vaccines and cures against the coronavirus so far, and the literature gap about the impact of the COVID-19 pandemic on approaches to innovation in the consulting industry, a grounded theory approach was used in this study to generate a theoretical explanation of how the COVID-19 is affecting the strategies and approaches of businesses in harnessing innovation opportunities from iterative collection and analysis of consulting professionals' perspectives (Creswell \& Poth, 2018).

After the transcription of each interview recording, memoing, open coding for code classification, axial coding in interpretation activities, and selective coding in theoretical framework generation, have been executed for qualitative data analysis (Creswell \& Poth, 2018). Furthermore, the research process revolved around five main interactive qualitative research analysis phases: compiling the collected field notes and data into a database, diassembling the compiled data into smaller pieces or fragments, reassembling and reorganizing the fragments into sequences or sets, interpreting the reassembled data to produce a narrative and then concluding (Yin, 2015). It should be noted that the interpretations followed the description-and-call-for-action as an interpretation approach (Yin, 2015).

\section{Participants}

Purposive sampling was used to select three to five employees in the consulting industry whose job responsibilities were focused on innovation and who have been employed before and during COVID-19 pandemic. As exclusion criteria, candidate participants that were not employed pre-COVID were not recruited. The researcher targeted a list of consulting companies that existed prior to the COVID-19 pandemic and were still operating at the time of the study. Email addresses were obtained from their public corporate websites, and an invitation to participate were emailed to possible participants. A copy of this invitation is in Appendix 1. Each participant was asked if they knew someone who would be willing to participate in this study. As a result, participants were also recruited via snowball sampling. The response rate was $100 \%$ as a sample of size $n=4$ was constituted as follows: one male regional data and practice manager who was also a hands-on software engineer, one male regional delivery manager, one female salesperson and one female marketing manager.

\section{Data collection and instrumentation}

Once the IRB approval was received, the researcher used the public e-mail addresses of targeted consulting firms to invite employees at those companies whose job responsibilities were focused on innovation. Thereafter, each of those employees was contacted via e-mail to make them aware that an interview would last approximately 60 minutes and to set up an 
interview time that worked best for them. A copy of the interview questions is in Appendix 2. No payments were made to the study participants.

Due the social distancing measures in place during this COVID-19 pandemic, each interview was conducted over the phone or via Microsoft Teams, depending on the participant's preference. Audio recording of interviews is a standard protocol for qualitative research. Recording the interviews captures the actual words of the participants, and this assures all the thoughts, perspectives and experiences of the participants are accurately portrayed (Yin, 2015). Telephone interviews were recorded on a Sony ICD-UX570 Digital Voice Recorder and video interviews were recorded via Microsoft Teams.

Each signed and scanned letter of consent was stored in one encrypted file on the student researcher's password protected computer. Hard copies of the letters of consent were stored in a separate locked file cabinet at the researcher's home. Scanned copies will be deleted, and hard copies will be shredded three years after the research is completed.

\section{Data analysis}

The researcher transcribed the audio and video recorded interviews. No names were associated with the recordings or the transcripts as they were labeled using only numbers (P1, P2, etc.). Recordings and digital transcriptions are stored in encrypted files on the researcher's password protected computer, and they will be deleted three years after the research project is completed.

The researcher read through the transcribed text while making margin notes and forming initial codes (Creswell \& Poth, 2018). Following the guidelines of Strauss and Corbin (1998), the researcher performed in a recursive manner:

(1) Open coding: categories were generated and described based on their dimensions/ properties (originating conditions, embedding context, actions/interactions and consequences).

(2) Axial coding: relationships between categories' properties were identified based on data observations.

(3) Selective coding: theoretical statements were generated to integrate the categories and unveil the emerging theoretical framework. The central category/theme was identified.

(4) Data visualization: the generated theoretical framework is depicted in Figure 1.

\section{Ethical considerations}

The following measures were taken in this study to tackle the top two ethical issues related to data analysis:

(1) protection of participants from harm: participants were assigned numbers (Creswell \& Poth, 2018)

(2) disclosure of comprehensive findings: member-checking strategies and opportunities for sharing procedures and results were embedded and multiple perspective reflective of a complex picture were presented (Creswell \& Poth, 2018).

Prior to the initial online meeting for the initial interview with each study participant, the researcher explained via email and/or phone call the purpose of the study, interview recording and transcription procedures, study artifact's storage, and requested lecture and signature of the informed consent form. As part of the consent process, before each initial interview began, the researcher asked the participant if the individual acknowledges being audio/video recorded and that acknowledgement would be recorded. 
Memoing helped in tracking the development of ideas and earning credibility in qualitative data analysis (Creswell \& Poth, 2018). In addition, iterative data collection, categories saturation, details in coding and categories generation, explanation of resulting theoretical framework and interpretations helped to drastically reduce coding problems and other data analysis issues. The researcher generated a rich and dense description of study settings and participants' data inputs to help establish the transferability of the study (Creswell \& Poth, 2018). Moreover, the researcher also requested feedback from the primary investigator. Peer reviews from classmates and scholars also served the same purpose.

\section{Study results}

Each participant in this pilot study was employed at an IT consulting firm before and during the COVID-19 pandemic. The participants all worked around innovation whether in sales, engineering, marketing or management, and some fulfilling more than one job positions. The research process revolved around five main interactive qualitative research analysis phases: compiling the collected field notes and data into a database, diassembling the compiled data into smaller pieces or fragments, reassembling and reorganizing the fragments into sequences or sets, interpreting the reassembled data to produce a narrative and then concluding (Yin, 2015). It should be noted that the interpretations followed the descriptionand-call-for-action as an interpretation approach (Yin, 2015).

This section will present the empirical findings of the pilot study created following the grounded theory approach proposed by Strauss and Corbin (1998).

Open coding and axial coding

After generating codes and classifying them into themes from the built open coding matrix, the following categories and subcategories of themes in Table 1 below were generated.

\begin{tabular}{ll}
\hline Categories & Subcategories \\
\hline Environmental change and innovation & - COVID-19 pandemic global impact \\
opportunities & - Budget cuts \\
& - Heavy clients' migration to the cloud \\
& - Lack of in-person collaboration \\
Job-to-be-done strategy & - Market trends' tracking \\
& - New marketing tactics \\
Organizational support & - Soundaryless or national consulting firm \\
& - Flexibility in working arrangements \\
Innovation and preparation for new & - Hard-working managers \\
normal & - Value co-created \\
& - Satisfied clients \\
& - Profit generation \\
& - Organizational restructuring \\
& - Remote work as option in new normal \\
& - In-office work for demanding clients and for consulting firm \\
& culture reparation
\end{tabular}

Table 1.

Axial coding: conceptualized categories and subcategories of themes
- COVID-19 pandemic global impact

- Heavy clients' migration to the cloud

- Changing client needs

- Lack of in-person collaboration

Market trends' tracking

- Strong and reliable network and procurement

- Flexibility in working arrangements

- Value co-created

- Satisfied clients

- Profit generation

Remote work as option in new normal culture reparation 
Environmental change and innovation opportunities. The COVID-19 pandemic has affected the world, and the consulting industry in particular, both positively and negatively. In fact, one of the participants reported that "it's been interesting just to watch where like some industries have heavily increased and some have just had to pivot their budget, in order to even be able to keep up with their actual employees." Some projects got canceled or abandoned because of clients' budget cuts and/or shift in priorities.

Considering the abandoned or canceled projects and the slight uncertainty in company activities during the COVID-19 pandemic, a participant mentioned that in "2019 we did exceed our quota. Uhm, moving into 2020, our pipeline is there online. We are on track to continue hitting a quota, but due to the pandemic in COVID there's definitely a lot of changes and shifts just based off of different customer budget."

As all participants mentioned, some client companies performed very good during the pandemic while others have been struggling, leading to massive layouts, heavy migrations to the cloud and the success of e-commerce.

Participants stressed the lack of in-person collaboration brought by the COVID-19 pandemic. It was the most popular and over-populated code throughout the interviews. Participants listed several challenges and opportunities from the lack of in-person collaboration by describing.

(1) The lack of physical contact/physical space sharing. For example, a participant reported: "We used to go... To a couple of conferences a year and be able to get together in person and have that time for just casual conversation, but that would evolve in ideas, sharing knowledge, sharing and stuff like that."

(2) A significant decreased in informal conversations; a participant affirmed that with online meetings, "you go straight to the meetings instead of like, usually you get to know the people a little bit and you're there and you."

(3) Decrease in visual contact. For example, about online meetings, a participant stated: "I think it's very much scheduled. It's very much, you know, many times without a video camera. There are some members of my team I haven't seen in a year now. I've only heard their voice. And it's scheduled. It's timed a lot. It's like 'OK, time's up now I gotta go talk to the next person' and you fill up your day with half hour meetings after half hour meetings."

(4) Meeting fatigue. For example, a participant said: "So you kind of have that meeting fatigue, especially video meeting fatigue."

(5) Reduced contact in extra-organizational professional networks; a participant stated that "by the time people were done with the meetings of the day, there just was no energy for more of the same outside of the normal work environment". Another participant added that "now you have to like, feel motivated, so like pick up phone or schedule the meeting to get back with people outside of your work network."

Organizational support. Participants described their company as one with a high flexibility and a strong ability to easily switch to telework. One participant stated: "I mean, even like our network bandwidth that we have. Some companies can't even do video because they can't even hold all the bandwidth of their employees. So, we as a company that different type of part of OurCompanyX did leverage a lot of our procurement side, our partners or different laptops for different types of initiatives."

There has been a lot of efforts from management for team building and fluent collaboration, including virtual baby showers and virtual happy hours. For example, one of the managers in the sample specified about their attempt to recreate informal team
Innovation in the consulting industry

$\longrightarrow$


conversations: "It's not anything other than let's replicate conversations that would have happened if we were sitting next to each other [...]. It's like trying to force a sense of team, trying to form a sense of unity and just let us talk about whatever without needing to be a structured meeting." In addition, the participants' employer fostered efforts to create a warm and collaborative organizational culture during the pandemic as one participant stated: "we just are trying to reboot our Culture Club to, you know, kind of reinvent and refresh some ideas on how we can engage and how we can be there for our employees on our teammates in in 2021 so. That's a that's a challenge."

Job-To-Be-Done strategy. As a standard consultancy, the strategy and the core of the novel idea recognition process of the employer in the study sample has been to follow market trends in order to innovate, better compete and succeed. One study participant explicitly said that "it's all about trying to read the market where the market is going." As soon as the COVID-19 pandemic pushed the world into canceled gatherings, socially distanced life and masks, most companies decided to move their software systems into the cloud. All participants pointed that the heavy migration of client companies into the cloud led their company to strategically focus in helping organizational cloud migration while developing their connected platform idea generated in 2019. That novel idea has been strengthened with a detect-and-prevent solution which perfectly fits in the current pandemic settings. One participant affirmed about the connected platform idea: "basically take this connected platform which is this prebuilt thing and basically, you know, think of that as 70, 80\% of projects we've already done. We can sell that and then customize the rest for somebody who is really kind of know how the Connected Platform works."

While continuously tracking market trends the IT consulting firm designed and implemented new marketing tactics, as one participant mentioned about changes in marketing that "what changed is, the tactics and the channels of how we were going to reach people."

Thanks to the global telework trends, the participants' employer has been able to operate like a single national firm with no physical boundaries. In fact, client companies recruited consultants from different cities and states, and were pleased with the results. For example, a participant reported about the telework consequence of the COVID-19 pandemic that "it really opened up our ability to staff projects with the right people and not just the closest people." Also, more than before, several staff members throughout the organization found themselves working for company branches other than or in addition to their local company branch as one study participant stated: "We were probably borrowing and lending about 12 people. OK, so it's probably doubled, the amount of sharing of people that we were doing in other offices."

Operating as a boundaryless company is an opportunity brought by the COVID-19 pandemic that the participants have been able to recognize and fully exploit as a company. In fact, the employer reacted to the pandemic in multiple ways, including organizational restructuring for company-wide conversations and decision-making as one participant stated: "We were actually changing compensation models and financials to help facilitate that more and help to knock down some of that franchise model. We just re-orged again as a result of a lot of learnings over 2020, much of which were as a result of the impact of COVID on our organization."

Innovation and new normal. Regarding the new normal business life after the pandemic, the participants did not express apprehension or impatience. One participant said about the pandemic: "after that, I think if people want to work remotely, I think they'll probably will have the option." They pointed that there will probably be a new normal work life with delayed in-office return and possibly partial required office presence, if not optional, for their consulting firm. The in-office work will probably happen just for the company culture or as a necessity for client companies. In fact, their company's culture thrives from in-person exchanges and collaboration. Moreover, all the participants mentioned that the staff at their 
consulting firm has quickly and efficiently adapted to the remote work settings. During the COVID-19 pandemic, the performance has been high and online collaboration has evolved as one manager stated: "Once you like, it's your only option is to pick up the call because you can't walk down the hall, then it becomes a more comfortable, natural part of your like collaboration process."

Still following market trends, participants foresaw the connected platform started in 2019 as a service that they will keep improving and offering in the new normal post-COVID for a significant amount of time. Regarding the applications of the connected platform and the detect-and-prevent product initiative, one participant stated: "But you will also see there's a lot of other applications to similar situations that we can use [...]It is a longstanding solution and we have clients, big clients that are that are looking for definite future phases and an addons and improvements and changes to the platform. So I do believe it's here to stay and it's going to be a solution that one of the things that we've showed is that we can definitely pivot to the needs of current. . . our current clients."

\section{Selective coding}

Using the research question above, the three emerging themes are: environmental change and innovation opportunities, Job-To-Be-Done strategy, and innovation and preparation for the new normal. Despite the saturation of the lack of in-person collaboration code, the central theme of this study is the Job-To-Be-Done strategy because besides connecting all the other themes, it is the primary driver of the novel idea generation/recognition and novel idea exploitation processes.

\section{Theoretical framework}

The generated theoretical framework (final model) is depicted in Figure 1 below.

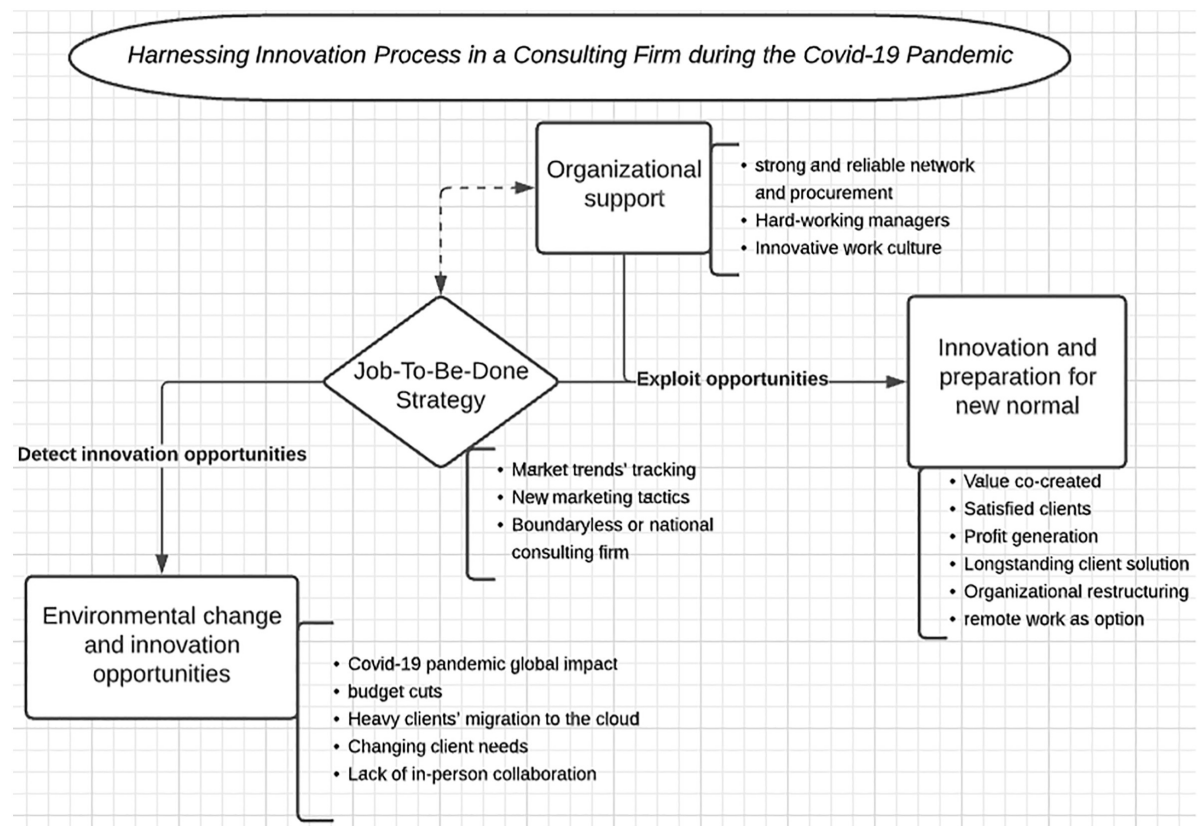

Innovation in the consulting industry

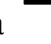




\section{Discussion}

The aim of this pilot study was to examine the changes brought by the COVID-19 pandemic on approaches or models to innovation in the consulting industry. Using a grounded theory approach to analyze the perspectives of professionals from consultancies, this aim was achieved by identifying new innovation patterns in the consulting industry, examining novel idea exploitation approaches in the consulting industry and identifying potential capabilities that can help improve approaches to innovation in the consulting industry.

The study findings revealed the Job-To-Be-Done strategy as the central study theme connected to all the other themes (Strauss \& Corbin, 1998) as depicted in the study theoretical framework in Figure 1 above.

From the tip of the iceberg, there seems to be no major change in novel idea generation/ recognition process for salespeople, managers and engineers during the COVID-19 pandemic. But from the submerged part of the iceberg, there were global environmental changes. The lack of personal contact reduced informal conversations and decreased contact with professionals from extra-organizational networks have clouded the idea generation, recognition and exploitation processes. The shift to remote work settings has put employees in custom work environments where meeting fatigue and workload balance struggles thrive. Intraorganizational collaboration has become more intense and formal, making it a little difficult to have off-topic discussions and elaborate on green ideas. Extraorganizational collaboration has heavily decreased mostly due to meeting fatigue. According to White (2021), more than $42 \%$ of the workforce transitioned to teleworking in 2020. Some teleworkers have experienced burnouts during the COVID-19 pandemic from issues including amongst others stress, lack of guidelines or formal policies on telework settings and poor ergonomics (White, 2021).

Gajic, Lalic, and Stankovic (2013) argued that, in each company, organizational intelligence and individual intelligence interact together to create, recognize and implement novel ideas that can bring values to the firm. This statement was further supported by Ovans (2015) who claimed that people's talent and processes are needed in equal weights to drive organizational innovation.

The staff of IT consulting firms could not fully leverage the organizational gatherings and in-office organizational infrastructure, but they could take advantage of robust organizational support equipment and increased management efforts. Popa (2016) demonstrated with his seven-phase affect-centered model of work motivation that employers need to really connect with their staff members in order to better motivate them, foster employee wellbeing, staff creativity and innovation. Marketing saw a shift in novel idea generation/recognition process, particularly in terms of communication of leaders' instructions and decisions to the marketing team, and gifts mailing to targeted people. A business strategy oriented towards locating poorly performing jobs (Christensen et al., 2016) at client companies helped the consulting firm in the study sample detect opportunities, implement solutions, co-create value, generate profit, and foresee and prepare for potential jobs. Regarding problems related to the lack of in-person communication such as ineffective information exchange and incorrect perceptions of communication, Newman, Ford, and Marshall (2019) suggested mitigation measures such as asynchronous communications, instant messaging and video meetings, sharpened leader's responsiveness and mostly team adaptation.

Armed with similar measures, a Job-to-be-Done strategy, continuous market screening and pronounced management support, the consulting firm in the study sample has been able to quickly adapt, innovate and compete with the future in mind. Mixed locations teams within the consulting firm benefited from the COVID-19 pandemic from the eliminated work travels, increased meetings and emphasis on collaboration with each other no matter the 
localizations. Therefore, consulting firms can successfully innovate and generate profit during global crisis as postulated in the Job-To-Be-Done theory (Christensen et al., 2016).

Dynamic capabilities research aims at understanding how firms can sustain a competitive advantage by responding to and creating environmental change (Helfath \& Peteraf, 2019). This study showed that an outcome-driven strategy can help a firm survive and compete despite the global environmental change brought by the COVID-19 pandemic, hence adding empirical evidence to support both the Job-To-Be-Done theory and the dynamic capabilities framework.

\section{Substantive theory}

Based on thick descriptions of participants' perceptions and experiences, and based on a detailed Straussian grounded theory analysis that led to the theoretical framework in Figure 1, the following substantive theory emerged:

Organizational leaders' increased responsiveness, a Job-To-Be-Done strategy, organizational support and team adaption are the keys to harvesting dynamic capabilities for better competition, even during global environmental changes.

\section{Contributions and implications}

From the proposed substantive theory above, this pilot study contributes in:

(1) Showing business leaders how firms can proactively implement outcome-driven strategies to survive, compete and generate profit, despite the global environmental change caused by the COVID-19 pandemic

(2) Strengthening the Job-To-Be-Done theory and the Dynamic capabilities framework

(3) Reminding innovation strategists, business professionals and scholars that a successful business innovation strategy should be able to evolve and adapt to the changing market conditions (Pisano, 2015).

(4) Laying the ground for future research on approaches to innovation.

Managers are crucial in building organizational dynamic capabilities. For dynamic capabilities to occur, managers should effectively communicate and/or have strong intentions to change the status quo because subordinates with strong intentions to change the status quo can encounter powerlessness, resulting in negative consequences such as health deterioration and resignation intentions (Kurtmollaeiv, 2020). In addition, based on the high productivity and profit generation in consultancies during the COVID-19 pandemic, clients and consulting firms should brainstorm and agree on new ways to offer telework flexibility to consultants.

Moreover, innovators should take advantage of the benefits of the current digital assets and redesign the world such as to fully exploit the changes brought by the pandemic, instead of trying to bring things back to the way they were pre-COVID (Euchner, 2020).

\section{Limitations and future research directions}

This pilot study sample was limited to only four participants from different roles but employed at the same IT consulting firm on a full-time basis in the USA. Future studies on approaches to innovation should include a larger number of professionals from diverse types of consulting firms situated in diverse locations.

Also, there is a rising question about capacity absorption and innovation diffusion (Moore, 2005) once a value is co-created in a client company. Using the substantive theory from tis 
pilot study as a starting point, future researchers might be able to advance the innovation diffusion theory (Dearing \& Singhal, 2020) and the absorptive capacity theory by further investigating the role of consulting companies in innovation diffusion and absorption.

\section{Conclusion}

The pandemic COVID-19 is ongoing and the best way to learn how the COVID-19 is affecting the strategies and approaches of businesses in recognizing and exploiting innovation opportunities is to conduct field investigations where workers that have been dealing with innovation during this pandemic would be interviewed about the research topic. Grounded theory helped generate that understanding from data collected on consulting professionals during the current global environmental changes. The Job-ToBe-Done strategy and the dynamism of IT consultancies helped them quickly switched their mindsets from local to national collaboration, pushed them to create long-term adaptable service offerings and efficiently serve clients. The primary benefit of this pilot study is that it explored new patterns in the way consulting companies that survive the COVID-19 pandemic identify and exploit innovation opportunities in the consulting industry. Those patterns added to the body of knowledge on approaches to innovation, the Job-To-Be-Done theory and the dynamic capabilities framework, while guiding modern business leaders on how to strategically innovate, compete and generate profit. Besides those research concepts/frameworks/theory, future studies on this research topic can also contribute to the innovation diffusion theory and the absorptive capacity theory. Another benefit is that this pilot study helped remind innovation strategists, business leaders and scholars that a successful business innovation strategy should be able to evolve and adapt to the changing market conditions (Pisano, 2015).

\section{References}

Alves, M. F. R., Galina, S. V. R., \& Dobelin, S. (2018). Literature on organizational innovation: Past and future. Innovation and Management Review, 15(1), 2-19. doi: 10.1108/INMR-01-2018-001.

Apostolou, D., \& Mentzas, G. (1999). Managing corporate knowledge: A comparative analysis of experiences in consulting firms. Part 1. Knowledge and Process Management, 6(3), 129-138. doi: 10.1002/(SICI)1099-1441(199909)6:3<129::AID-KPM64>3.0.CO;2-3.

Bruhn, M., Karlan, D., \& Schoar, A. (2018). The impact of consulting services on small and medium enterprises: Evidence from a randomized trial in Mexico. Journal of Political Economy, 126(2), 635-687. doi: 10.1086/696154.

Burkus, D. (2013). Innovation: Innovation isn't an idea problem. Harvard Business Review Digital Articles, 1-4. Available at: https://web-b-ebscohost-com.suscorp.idm.oclc.org/ehost/pdfviewer/ pdfviewer?vid=8\&sid=db3c37c2-98e1-4187-9e1c-33bfb2987b94\%40pdc-v-sessmgr06.

Christensen, C. M., Hall, T., Dillon, K., \& Duncan, D. S. (2016). Know your customers' “jobs to be done”. Harvard Business Review. Available at: https:/hbr.org/2016/09/know-your-customers-jobs-tobe-done.

Creswell, J. W., \& Poth, C. N. (2018). Qualitative inquiry and research design: Choosing among five approaches (4th ed.). Los Angeles: Sage Publications.

Cui, T., Tong, Y., Teo, H.-H., \& Li, J. (2020). Managing knowledge distance: IT-enabled inter-firm knowledge capabilities in collaborative innovation. Journal of Management Information Systems, 37(1), 217-250. doi: 10.1080/07421222.2019.1705504.

Dearing, J. W., \& Singhal, A. (2020). New directions for diffusion of innovations research: Dissemination, implementation, and positive deviance. Human Behavior and Emerging Technologies, 2, 307-313. doi: 10.1002/hbe2.216. 
Euchner, J. (2020). What comes after what comes next. Research Technology Management, 63(4), 9. doi: 10.1080/08956308.2020.1762442.

Filatotchev, I., Aguilera, R. V., \& Wright, M. (2020). From governance of innovation to innovations in governance 1. Academy of Management Perspectives, 34(2), 173-181. doi: 10.5465/amp. 2017.0011.

Gajic, S., Lalic, D., \& Stankovic, J. (2013). The role of individuals in the process of innovation. In 6th International Conference for Entepreneurship, Innovation and Regional Development (ICEIRD 2013) (pp. 412-418). Available at: https://www.researchgate.net/publication/267263430_The_ role_of_individuals_in_the_process_of_innovation.

Hamel, G. (2015). Innovation starts with the heart, not the head. Harvard Business Review Digital Articles, 2-6. Available at: https://web-a-ebscohost-com.suscorp.idm.oclc.org/ehost/pdfviewer/ pdfviewer?vid=3\&sid=44c21ac2-d0f1-4737-816a-d9e6c0c0ab53\%40sdc-v-sessmgr01.

Helfath, C. E., \& Peteraf, M. A. (2019). Understanding dynamic capabilities: Progress along a developmental path. Strategic Organization, 7(1), 91-102. doi: 10.1177/1476127008100133.

Jiang, Y., Jiang, X., Tong, W., \& Zhou, J. (2020). Quantitative analysis and mathematic modeling of the global outbreak of COVID-19. Journal of Infection in Developing Countries, 14(10), 1106-1110. doi: $10.3855 /$ jidc. 13150 .

Kurtmollaiev, S. (2020). Dynamic capabilities and where to find them. Journal of Management Inquiry, 29(1), 3-16. doi: 10.1177/1056492617730126.

Lin, P., Zhang, X., Yan, S., \& Jiang, Q. (2020). Dynamic capabilities and business model innovation of platform enterprise: A case study of DiDi Taxi. Scientific Programming, 1-12. doi: 10.1155/2020/ 8841368.

Luecke, R., \& Katz, R. (2003). Managing creativity and innovation. Boston: Harvard Business School Press.

Moore, G. A. (2005). Dealing with Darwin: How great companies innovate at every phase of their evolution. New-York, NY: Portfolio.

Newman, S. A., Ford, R. C., \& Marshall, G. W. (2019). Virtual team leader communication: Employee perception and organizational reality. International Journal of Business Communication, 57(4), 452-473. doi: 10.1177/2329488419829895.

O'Leary, D. E. (2019). Enterprise crowdsourcing innovation in the Big 4 consulting firms. Journal of Emerging Technologies in Accounting, 16(2), 99-118. doi: 10.2308/jeta-52433.

Ovans, A. (2015), (February 27). Is innovation more about people or process. Harvard Business Review. Available at: https://hbr.org/2015/02/is-innovation-more-about-people-or-process.

Parmar, R., Mackenzie, I., Cohn, D., \& Gann, D. (2014). The new patterns of innovation. Harvard Business Review, 92(1/2), 86-95. Available at: https://web-b-ebscohost-com.suscorp.idm.oclc.org/ ehost/pdfviewer/pdfviewer?vid=0\&sid=22b9ce6c-0297-4eac-925a-58597bd184e1\%40pdc-vsessmgr04.

Pillai, D., Nagappan, N., Dharani, S., Subramanian, K., Champakesan, B., \& D’Cruz, T. M. (2020). Socioeconomic impact of coronavirus disease 2019 (COVID-19) - An Indian outlook. Journal of Family Medicine and Primary Care, 9(10), 5103-5106. doi: 10.4103/jfmpc.jfmpc_835_20.

Pisano, G. P. (2015). You need an innovation strategy. Harvard Business Review, 93(6), 44-54. Available at: https://web-a-ebscohost-com.suscorp.idm.oclc.org/ehost/pdfviewer/pdfviewer? vid $=0 \&$ sid $=3 \mathrm{e} 25 \mathrm{e} 0 \mathrm{cc}-\mathrm{a} 28 \mathrm{a}-4 \mathrm{e} 85-\mathrm{b} 308-\mathrm{e} 425136 \mathrm{e} 61 \mathrm{f9} \%$ 40sessionmgr4008.

Popa, M. (2016). The affective dimension of work motivation. Managerial Challenges of the Contemporary Society, 9(2), 46-53. Available at: https://web-b-ebscohost-com.suscorp.idm.oclc. org/ehost/pdfviewer/pdfviewer?vid=0\&sid=56a98521-cde1-48ad-8688-b43f9e507cc4\%40pdc-vsessmgr05.

Ribeiro, Á., Monteiro, P., \& Luttembarck, L. (2018). The use of the "job to be done" methodology to identify value co-creation opportunities in the context of the service dominant logic. Brazilian Business Review, 18(4), 1-14. doi: 10.15728/bbr.2019.16.1.3. 
Santos, J. B. (2019). Knowledge-intensive business services and innovation performance in Brazil. Innovation and Management Review, 17(1), 58-74. doi: 10.1108/INMR-03-2019-0025.

Strauss, A. L., \& Corbin, J. (1998). Basics of qualitative research: Techniques and procedures for developing grounded theory (2nd ed.). Newbury Park, CA: Sage Publications.

White, G. (2021). Burnout: Helping employees avoid and weather the challenges of working from home. Professional Safety, 66(5), 16-19. Available at: http://www.asse.org/professional-safety/.

Yin, R. K. (2015). Qualitative research from start to finish. New York: The Guilford Press.

\section{Appendix 1 \\ Invitation to participate in a research project \\ Dear potential participant:}

I am conducting a qualitative study to investigate how the COVID-19 pandemic affected the way businesses in the consulting industry harness innovation opportunities. My goal is to identify the new business innovation practices or patterns that emerged during the COVID-19 pandemic.

Harnessing innovation opportunities refers to recognizing and exploiting innovation opportunities.

For this pilot study, I am looking for 03 to 05 participants in the consulting industry who work around innovation for interviews. If you accept my invitation, I will interview you in a semi-structured interview format by phone or on Microsoft Teams according to your preferences. These interviews will be video and/or audio recorded, and I will identify each recording by using a pseudonym. The interviews are strictly confidential. Moreover, I will conduct telephonic interviews or online interviews from my home to maximize privacy.

The initial interviews will last approximately one hour. I may conduct a follow-up interview with you if I need additional information, and the follow-up interviews may last an hour.

If you would like to participate, or if you need more information, please contact me at dkamni7847@, sullivan.edu. Thank you for your help with this exciting project.

If you know of anyone currently working around innovation in the consulting industry, please feel free to pass along this invitation to participate in my study.

Diane Laurette Kamning

Doctoral Student at Sullivan University.

502.413.8774.

Sullivan University.

3101 Bardstown Road.

Louisville, KY 40205.

\section{Appendix 2 \\ Interview questions}

(1) What are the services and/or products provided by your employer?

(2) What is your role at your company?

(3) How many novel product or services had your employer offered to its customers in 2019? How many in 2020?

(4) How is your current workflow and related business processes compared to pre-COVID?

(5) Why in your opinion did that change occurred and how long do you think it will last?

(6) Prior to the COVID-19 pandemic, that is, before year 2020, how did you come up with novel ideas whether to improve your work or to help the whole organization to create new product or services?

(7) During the COVID-19 pandemic, that is, before year 2020, how did you come up with novel ideas whether to improve your work or to help the whole organization to create new product or services? 
(8) Once a novel idea has been identified, how do you proceed in exploiting it whether to improve your work or to help the whole organization to create new product or services prior to the COVID-19 pandemic?

(9) Once a novel idea has been identified, how do you proceed in exploiting it whether to improve your work or to help the whole organization to create new product or services during the COVID-19 pandemic?

(10) How has the collaboration with your colleagues changed with the COVID-19 pandemic?

(11) In your professional networks, how has the exchange of ideas been affected by the COVID-19 pandemic in your opinion?

\section{Corresponding author}

Diane Laurette Kamning can be contacted at: kamningd@gmail.com

For instructions on how to order reprints of this article, please visit our website:

Innovation in the consulting industry 